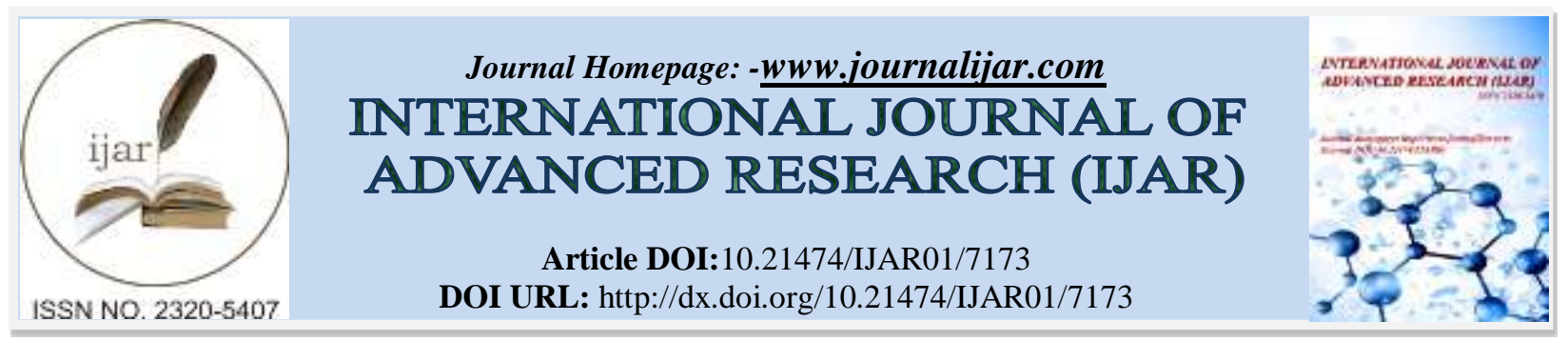

RESEARCH ARTICLE

\title{
A STUDY ON OUTCOME OF FAT GRAFT MYRINGOPLASTY.
}

\section{Dr Raja Ganesh MS ENT ${ }^{1}$, Dr T Sivasubramanian MS DLO ${ }^{2}$ and Dr Dhanalakshmi, PG in ENT ${ }^{3}$.}

1. Assistant Professor, Dept of ENT, Madurai Medical College.

2. Assistant Professor, Dept of ENT, Madurai Medical College, Madurai.

3. Madurai Medical college, Madurai.

\section{Manuscript Info}

Manuscript History

Received: 22 March 2018

Final Accepted: 24 April 2018

Published: May 2018

Keywords:-

Fat . ear lobule, myringoplasty,

abdominal fat.

\section{Abstract}

Copy Right, IJAR, 2018,. All rights reserved.

\section{Introduction:-}

Tympanic membrane perforation is mostly due to infection, trauma or Post Tympanostomy tube insertion. Mostly it heals spontaneously; however recurrent infection may interfere with regenerative process and result in chronic perforation. Myringoplasty is one of the most commonly performed otologic surgical procedures, which involves use of graft material to repair of tympanic membrane perforation. Since the development of Myringoplasty surgery, various graft materials have been used for repair of tympanic membrane perforation. These graft materials can be autologous, homologous or synthetic materials. Nowadays, Autologous temporalis fascia graft is the most widely used graft material followed by perichondium. Temporalis fascia graft needs external incision and possible visible scar which was used since 1950. The purpose of Fat Graft Myringoplasty is to repair such perforation and tends to improve hearing and eliminate the susceptibility to middle ear infection.

The Fat Graft Myringoplasty was $1^{\text {st }}$ introduced by Ringer berg ${ }^{28}$ in 1962 as an Office based Procedure.ear lobule fat was used as graft in this study. Fat graft Myringoplasty is done by transcanal technique cy using Otoendoscopic guidance. Mostly done under local anesthesia. patient can be discharged on the same day. This study evaluates the efficacy of fat graft myringoplasty.

\section{Aims And Objectives:-}

1. To evaluate the efficacy of the Fat Graft Myringoplasty with respect

2. To find out the success rate of closure of small dry central TM perforation / Graft uptake,

3. To compare the success rate of Fat Myringoplasty harvesting fat graft from different donor site ( Ear lobule / Abdominal fat),

4. To assess the operative outcome in correlation with site of perforation,

5. To evaluate as Day Care Procedure,

6. To find out the incidence of the complications if any. 


\section{Materials And Methods:-}

A Prospective Cohort Clinical study was carried out at Department of Otorhinolaryngology, Govt.Rajaji Hospital Madurai.

Time period of this study is 1 year, from August 1, 2016 to July 31, 2017. All patients between the age groups of 18-50 years attending to the ENT O.P.D. with complaints of ear discharge and deafness were screened by detailed history, clinical examination and otoendoscopy.

Forty patients were selected according to these following criteria:

CSOM with central perforation not exceeding 25\% area of Pars tensa of TM.

Dry perforation for at least 6-8 weeks

Perforation persistent for at least 6 months

Age : $18-50$ years

Normal appearance of middle ear mucosa

PTA showing Conducive hearing loss with Air Bone gap $\leq 30 \mathrm{~dB}$

Small central perforation is confined to one quadrant or $<25 \%$ of Pars tensa of Tympanic membrane:-

Patient who had active ear discharge, history of previous ear surgery, with associated significant pathology in Middle ear cavity ( Cholesteatoma, Ossicular pathology, retraction), Tympanic membrane with Tympanosclerosis, Atrophic area or Pars flaccida retraction, marginal perforation, Sinusitis / History of Allergy or uncontrolled Systemic diseases were excluded from this study.

This study included 40 patients (24 males and 16 females) with a small dry central perforation of tympanic membrane that resulted from any of the following causes (infection, trauma or post Tympanostomy tube insertion).

\section{Preoperative evaluation by}

1. Otoendoscopic examination of central perforation - site, shape, margin, middle ear mucosal status.

2. According to site of perforation - Anterior, Posterior, Central

3. Pure tone audiogram - to rule out (COHL / SNHL) (ossicular pathology)

4. CT scan temporal bone - any associated middle ear / mastoid bone pathology

5. Diagnostic Nasal Endoscopic Examination to rule out Rhino sinusitis

6. Basic investigation for assessment for surgery.

(Basic investigations viz. $\mathrm{Hb} \%$, TC, DC, BT, CT, HIV, Hb- SAg etc. were done.)

\section{Study Group:-}

Site of perforation:-

Group a - Anterior (6)

Group B - Posterior (14)

Group C- Central (20) / Inferior

Site of fat harvesting:-

Group I - Ear lobule fat [28]

Group II - Abdominal fat [12]

Operation time

Total operation time

Surgical operation time

Total operating time was the time that the patient stayed in the operation theatre. Surgical operating time was the time from starting of the local infiltration till the end of surgical procedure.

Table 1:-SUBGROUPS

\begin{tabular}{|l|l|l|l|}
\hline $\begin{array}{l}\text { Donor site Vs perforation } \\
\text { site }\end{array}$ & Anterior & Posterior & Central/ inferior \\
\hline ear lobule fat & IA & IB & IC \\
\hline abdominal fat & IIA & IIB & IIC \\
\hline
\end{tabular}


The detail procedure was explained in the vernacular language and those patients willing to give written consent underwent fat graft Myringoplasty. All cases were operated under local anesthesia with prior prophylactic oral antibiotic medication. Fat graft myringoplasty was done.

Patients were discharged on the same day. They received oral antibiotics for six days along with antihistamines.

\section{Post Operative Followup:-}

Regular follow up at least for 6 months (in the $1^{\text {st }}$ month weekly, bi weekly in $2^{\text {nd }}$ month, third month onwards monthly follows up)

Post Operative Success Rate assessed by

1. Graft uptake by Otoendoscopic examination after $8^{\text {th }}$ week.

2. Pure Tone Audiogram at $8^{\text {th }}$ week (hearing improvement in the form of closure of the air-bone gap)

3. Time taken for surgery and recovery

4. Complications of the procedure if any

\section{Observation:-}

The prospective cohort clinical study was carried out on 40 patients attending ENT OPD, Govt.Rajaji hospital, Madurai in the period of one year from August 1, 2016 to July 31, 2017. The ages of the patients ranged from 18 to 50 years with mean age of 31.97 years. The minimum age in the study was 19 years, and the maximum age was 47 years. The maximum numbers of patients were found in the age group of 26 to 35 years. There were 24 male $(60 \%)$ and 16 female $(40 \%)$ patients showing male preponderance with male to female ratio of $1.5: 1$.

Age and sex wise distribution of cases:

\begin{tabular}{|l|l|l|l|}
\hline AGE & MALE & FEMALE & TOTAL \\
\hline $15-25$ & 7 & 2 & 9 \\
\hline $26-35$ & 11 & 6 & 17 \\
\hline $36-50$ & 6 & 8 & 14 \\
\hline Total & 24 & 16 & 40 \\
\hline
\end{tabular}

All the patients had complaint of ear discharge and associated with hard of hearing and / or ear pain.

Aetiology Of Perforation:-

\begin{tabular}{|l|l|l|l|}
\hline AGE & INFECTION & $\begin{array}{l}\text { POST } \\
\text { TRAUMA }\end{array}$ & $\begin{array}{l}\text { POST TNSERTION } \\
\text { INSERANOSTOMY }\end{array}$ \\
\hline $15-25$ & 5 & 2 & 2 \\
\hline $26-35$ & 11 & 6 & 0 \\
\hline $36-50$ & 6 & 8 & 0 \\
\hline TOTAL & 22 & 16 & 2 \\
\hline
\end{tabular}

Out of 40 patients, 22 patients (55\%) had infectious etiology, 16 patients (40\%) had traumatic cause and 2 patients $(5 \%)$ had post Tympanostomy tube insertion as a cause. Infection was the most common cause followed by trauma.

According to site of perforation, 20 patients (50\%) had central perforation, 14 cases $(35 \%)$ had posterior perforation and anterior perforation seen in 6 patients $(15 \%)$. Inferior or central perforation was the most common cause in our study.

\begin{tabular}{|l|l|}
\hline SITE OF PERFORATION & GROUP \\
\hline ANTERIOR PERFORATION & A \\
\hline POSTERIOR PERFORATION & B \\
\hline CENTRAL PERFORATION & C \\
\hline
\end{tabular}

\begin{tabular}{|l|l|l|l|}
\hline AGE & ANTERIOR & POSTERIOR & CENTRAL \\
\hline $15-25$ & 3 & 2 & 4 \\
\hline $26-35$ & 2 & 7 & 8 \\
\hline $36-50$ & 1 & 5 & 8 \\
\hline Total & 6 & 14 & 20 \\
\hline
\end{tabular}


Diagnostic nasal endoscopic examination and CT scan temporal bone were normal for all the subjects in this study.

Table 6:-

\begin{tabular}{|l|l|}
\hline EAR LOBULE FAT & I \\
\hline ABDOMINAL FAT & II \\
\hline
\end{tabular}

Out of 40 cases, ear lobule fat was used as graft in 28 patients (70\%) and abdominal fat in 12 patients (30\%).

\section{Graft Uptake:-}

Our study had successful graft uptake in 38 patients out of 40 patients and this was $95 \%$.

There were 23 males (95.8\%) and 15 females $(93.75 \%)$ in the successful graft group and there were 1 male and 1 female in the unsuccessful graft group. The difference between gender groups was statistically not significant. (P value- 0.657 )

The graft uptake with respect to site of perforation was as follow higher in posterior perforation (100\%) while central perforation had closure rate of $95 \%$ and $83.3 \%$ in anterior perforation. The different was statistically not significant. $\mathrm{P}$ value $>0.05$

When we classified patients according to site of perforation as anterior, posterior and central and analyzed its relationship with successful closure rates, in posterior perforation the closure rate was $100 \%$, in central perforation was $95 \%$ and finally in anterior perforation the closure rate was $83.3 \%$. The difference was statistically not significant.

In the evaluation of the effect of graft materials from different donor site on tympanic membrane closure, we studied, of the 28 ear lobule fat graft patients, 27 patients had successful closure and 1 had unsuccessful closure.

\begin{tabular}{|l|l|l|}
\hline DONOR SITE & SUCCESSFUL UPTAKE & FAILED CASES \\
\hline EAR LOBULE FAT & 27 & 1 \\
\hline ABDOMINAL FAT & 11 & 1 \\
\hline Total & 38 & 2 \\
\hline
\end{tabular}

Of the 12 abdominal fat graft patients, successful closure seen in 11 patients and one had residual perforation.

In both groups, there was no significant difference between graft sources.

The mean Total operation time was 42.87 minutes with standard deviation of $5.65 \mathrm{~min}$. The mean surgical operation time with standard deviation was $23.00+/-5.04$.

\begin{tabular}{|l|l|l|}
\hline \multicolumn{1}{|c|}{ Donor site } & Mean total operation time with SD & Mean surgical operation time with SD \\
\hline Ear lobule fat & $39.82+/-3.19$ & $20.36+/-2.69$ \\
\hline Abdominal fat & $50.00+/-3.02$ & $29.36+/-3.59$ \\
\hline
\end{tabular}

The time taken for the harvesting of the abdominal fat was more than ear lobule fat.

Out of 40 cases the preoperative PTA showed 16 cases had hearing threshold between 15 - $20 \mathrm{~dB}, 13$ cases had $21-$ $25 \mathrm{~dB}$ and 11 cases had $26-30 \mathrm{~dB}$ hearing threshold. The mean preoperative PTA average was $22.2 \mathrm{~dB}$.

\section{Post operative hearing gain is 2.89Db:-}

In our study we found, the mean preoperative hearing threshold $(\mathrm{dB})$ was $22.2 \mathrm{~dB}$ and after procedure the mean hearing threshold $(\mathrm{dB})$ was 19.4 and there was a mean gain of $2.89 \mathrm{db}$ which was statistically significant. (P value is 0.009). In the age group of 15 to 25 years, the mean preoperative PTA was $24.11 \mathrm{~dB}$, the mean postoperative PTA was $20.67 \mathrm{~dB}$ and the mean gain was 3.44 . In 26 to 35 years age group, the mean preoperative PTA was $21.47 \mathrm{~dB}$, the mean postoperative PTA was $18.67 \mathrm{~dB}$ and the mean gain was 2.74 . In the age group of 36 to 50 years, the mean preoperative PTA was $21.93 \mathrm{~dB}$, the mean postoperative PTA was $19.43 \mathrm{~dB}$ and the mean gain was $2.5 \mathrm{~dB}$. Out of 40 cases complications took place in 2 cases $(5 \%)$. One had residual perforation and other one had infection. The patient who had residual perforation, didn't come for follow up in the first postoperative month. With regard to site of perforation, One failure case seen in central perforation and one in anterior perforation. On the basis of etiology 
one failure case in infective etiology and one in post Tympanostomy tube insertion case. According to site of fat graft harvested one failure case in Ear lobule fat and one in abdominal fat graft.

\begin{tabular}{|l|l|l|}
\hline SUB GROUPS & RESIDUAL PERFORATION & INFECTION \\
\hline IA & 0 & 0 \\
\hline IB & 0 & 0 \\
\hline IC & 0 & 1 \\
\hline IIA & 1 & 0 \\
\hline IIB & 0 & 0 \\
\hline IIC & 0 & 0 \\
\hline
\end{tabular}

In our study 1 case had active ear discharge on $1^{\text {st }}$ follow up due to Acute Otitis Media, discharge was stopped with conservative management but finally ended up with residual perforation, and they were advised tympanoplasty. One other case had residual perforation which was surgically managed by type I tympanoplasty. The perforation size did not increase after surgery in any of our subjects, including those in whom the perforation remained open.

\section{Discussion:-}

The present study was prospective clinical cohort study. It was carried out to evaluate the efficacy of the Fat Graft Myringoplasty with respect to its success rate of small perforation of tympanic membrane in relation to site of perforation, site of fat graft harvested and as a day care procedure. In the present study, the age of the patient varied between $18-50$ years. In this age group there is less chance of upper respiratory infections and Presbyacusis.

The size of the perforation was determined by several parameters: the percentage of the pars tensa involved the number of involved quarters of the tympanic membrane, the diameter of the perforation, and the gross dimension of the perforation. Poor results from the repair of an anterior perforation may occur because the anterior edge of the perforation is usually partially obscured by the bulging of the anterior ear canal. As a result, the scarred margin may not be adequately refreshed. In such cases, Ayache $^{2}$ and colleagues suggest the use of otoendoscopy for better visualization of the anterior margin.

Endoscopic approach to the middle ear is a recent concept and it is minimally invasive. It has been successfully used in reconstruction of small to medium sized perforation.

Initially otoendoscope was used as a diagnostic tool to closely inspect the tympanic membrane and the middle ear structures. First use of the endoscope was done in the year 1967 by Mer et al. to examine the middle ear. Later on with the advent of rigid Hopkins rod telescopes, otoendoscopes are now routinely used for the examination of the intact tympanic membrane and its abnormalities and middle ear surgeries. In our study we used endoscopes for pre operative evaluation, operative procedure and post operative follow up for graft uptake.

There are basically 3 approaches to visualize the tympanic membrane, post aural, end aural, and transcanal. Of all these approaches used by the microscope, post aural and end aural approaches usually make an external incision and leave a scar and post operative morbidity. Further, in selected cases with wide and straight external auditory canal the transcanal approach rendered no external scar and minimal morbidity post operatively. Otoendoscope made this approach more popular in treatment of small central perforations with close inspection of the middle ear structures. In the literature, there are various graft materials that have been used for this method of transcanal endoscopic reconstruction of the tympanic membrane with small central perforation.

Transcanal technique is minimally invasive and has several advantages such as decreased surgical time, ease of learning, comfort to the patient, no hair shaving, no bandage, minimum medication, no complications of the post aural wound, and no need for hospitalization.

Conventional Myringoplasty with autologous temporalis fascia ha success rate of $100 \%$ for small perforation. But morbidity and cost of therapy is much higher for tympanoplasty.

Commonly used grafts include autologous temporalis fascia, perichondrium, cartilage and adipose tissue. Histologically, tympanic membrane grafts become lined by squamous epithelium on the ear canal side and middle ear mucosa on the tympanic cavity side. The graft itself becomes the middle or connective tissue portion of the 
reconstructed drum, but the orderly arrangement of concentric and radial collagen fibers as seen in the normal drum is not reconstituted in the graft.

In the present study, fat was harvested from ear lobule. Microscopic comparison of fat from 3 sources (ear lobule, abdomen, buttocks) showed that fat cells from ear lobule were more compact and contains fibrous tissue. Hani GI Garem et al in their study of fat Myringoplasty using different types of fat noted the success rate for ear lobule fat was $80 \%$, where as for abdominal fat was $73.3 \%$.

A study by Gian Antonio Bertoli et $\mathrm{al}^{39}$, suggested that guidelines for the harvesting of fat be followed. First, the fat must be harvested after the refreshment of the edges of the perforation. In a few patients, with a small ear lobe, the graft taken from the lobule club is too small because of the enlargement of the perforation. In those individuals, it was necessary to harvest the fat from the abdomen, a procedure that may also be required in patients who wear earrings. They modeled the adipose tissue into an hourglass shape, although other clinicians have preferred a champagne-cork shape or a bell shape. In their experience, the shape of the adipose tissue is not of great importance, although obtaining a fat graft that is 2 or 3 times larger than the perforation is essential. In their opinion, the infiltration of an anesthetic could artificially enlarge the volume of fat tissue in the ear lobe.

The advantages of fat graft include: It does not need support from the middle ear side to prevent collapse like underlay grafts especially at the area near the anterior annulus. Hagemann and Hausler ${ }^{14}$ noted closure of perforation in $91 \%$ of cases and hearing Gain of 5-10 dB. Chalishazar ${ }^{6}$ described closure of TM perforation in $90 \%$ cases by fat graft Mitchel et $\mathrm{al}^{24}$ described a review of 342 children who underwent fat graft Myringoplasty and achieved successful closure in $92 \%$ of ears.

Success rate in our study was $95 \%$.

Technical operative points during fat grafting (such as graft size in the perforation, degree of lateral bulge of the fat plug and moistening of the lateral side of the graft) are also considered to be important factors of success in the fat grafting procedure.

In this study, of the 28 ear lobule fat graft patients, 27 patients had successful closure and 1 had unsuccessful closure and out of the 12 abdominal fat graft patients, successful closure seen in 11 patients and one had residual perforation. In both groups, there was no significant difference between graft sources. From this study, we should also consider the abdominal fat for repair of small dry central perforation of TM.

Fat graft presents a big revascularization activity as seen by otoscopy a few days after the procedure. There is significant bulging on the tympanic membrane till the end of the third month postoperatively and after three months bulging of the fat graft progressively disappeared and converted into a smooth sclerotic area on the tympanic membrane at the fifth month. This phenomenon was also seen in all our successful patients in the postoperative period of 1-3 months.

The Trans canal approach seems to be safer for the patient in comparison to the classic Myringoplasty techniques since no manipulations of the middle ear are performed and the related complications are avoided. Fat is not the only material used when the tympanic membrane is approached via the external auditory meatus but it is somewhat easy to harvest and handle.

Free fat grafts have been known to reduce in size during long-term follow up. This is the reason why the grafts used were approximately two times larger than the size of the perforation. Nishimura $\mathrm{et}^{\mathrm{al}}{ }^{25}$ observed in an experimental study that apoptotic cells were present 30 days after transplantation. On the other hand the weight of the graft was significantly lower 180 days later. A weight loss of $20-80 \%$ is mentioned in the literature in adipose tissue grafts. A bulging on the tympanic membrane is present even 1 month after the operation but in the 12th postoperative week the graft is smoothly integrated with the tympanic membrane.

Ringer berg ${ }^{28}$ compared microscopically ear lobule fat, abdominal wall and buttock fat. The comparison showed that fat from ear lobule were found to be more compact and contain more fibrous tissue than other donor sites. This should provide a strongest and denser scaffold to allow for greater retention of the graft during epithelialization. 
However, Kwong et $\mathrm{al}^{46}$ asserted that this feature of ear lobe fat may complicate angiogenesis and tissue repair contrary to Ringer berg's observations and they manifested a clinical success of $100 \%$ using umbilical fat in their study.

The harvesting of the abdominal wall fat was technically easier; however it added the need of draping another surgical field in operative procedure. The postoperative care for abdominal incision necessitates an exposure that is not convenient for the usual ENT outpatient clinic.

The ear lobule fat has the advantage of same surgical field; however it is more difficult to harvest a fat plug especially if a large one is needed because of the possibility to injure the anterior skin of the ear lobule. The presence of piercing for ear rings in females further reduces the availability of the fat graft. In our study both the abdominal fat and ear lobule fat had same success rate for fat graft Myringoplasty.

Roee Landsberg et al. performed fat graft Myringoplasty on 38 perforations and found successful closure in 81.6\%. They also described significant improvement in speech reception threshold $(18.5 \pm 7.7 \mathrm{~dB}$ vs. $23.5 \pm 8 \mathrm{~dB})$.

38 out of 40 patients $(95 \%)$ showed good graft uptake. Preoperatively the mean hearing loss was 22.2 with standard deviation of 5.12. The postoperative pure tone audiometry was done after 2 months of surgery, which showed that average gain in hearing was $2.89 \mathrm{~dB}$. Postoperative pure tone audiometry, the mean was $19.4 \mathrm{~dB}$ with standard deviation of 4.24 , the mean hearing gain being $2.89 \mathrm{~dB}$.

Caye-Thomsasen et al (2007) in their study of 26 cases, the mean preoperative pure tone average was $20.1 \mathrm{~dB}$, the mean postoperative pure tone average was $11.5 \mathrm{~dB}$ and thus a hearing gain of $8.6 \mathrm{~dB}$.

Brown C et $\mathrm{al}^{45}$ (2002) in their study of 193 patients Myringoplasty, the mean preoperative air conduction average was $35 \mathrm{~dB}$ while the mean postoperative average was $25 \mathrm{~dB}$, thus average air conduction improvement was $10 \mathrm{~dB}$.

Average hearing gain in our study was $2.89 \mathrm{~dB}$.

\section{Conclusion:-}

In this study we have achieved a high success rate $(95 \%)$ for repair of small dry central perforation of tympanic membrane with fat graft.

Fat Graft Myringoplasty is a safe and effective technique for closure of small dry central perforation of TM. The advantages of this technique are simple, no need for GA, need minimal sedation, no need of hair shaving, less operating time, reduced otological trauma from manipulating tympanic cavity, faster recovery with no need of post operative dressing, cost effective, bilateral perforation can be repaired using fat graft in the same setting, minimum post operative morbidity.

It can be performed as an outpatient procedure, and the patient can be discharged on the same day. It causes minimal discomfort and high success rate after proper case selection.

Ear lobule fat can be easily harvested in a very short time and there is no visible scar and minimal donor site morbidity.

Abdominal fat graft is as effective as ear lobule fat, has cosmetic advantage, sufficient in quantity and should be taken into consideration when planning fat as the graft source.

The success rate of fat Myringoplasty is very high and comparable to the results of Temporalis fascia Myringoplasty.

So Fat Graft Myringoplasty is a successful simple procedure for repair of small sized perforation as a DAY CARE SURGERY. 


\section{Bibliography:-}

1. Althaus SR (1986) Fat plug Myringoplasty: a technique for repairing small tympanic membrane perforations. Same-Day Surg 10:88-89.

2. Ayache S. Braccini F. Facon F. Thomassin JM. Adipose graft

3. An original option in Myringoplasty. Otology \& Neurotology. 2003; 24:158-164.

4. Benson Mitchell R, Gardiner Q, Kenyon GS. Day stay Myringoplasty. J Laryngol Otol. 1996 May; 110(5):4214.

5. Bertoli GA, Barbaro M, Giangande V, Bava G, Seta ED, Filipo R. Fat graft Myringoplasty: An office procedure for the repair of small perforations of the tympanic membrane. Mediterr J Otol 2007; 3:120-5.

6. Chalishazar U (2005) Fat plug Myringoplasty. Indian J Otolaryngol Head Neck.

7. Surg 57:43-44

8. Deddens AE, Muntz HR, Lusk RP. Adipose Myringoplasty in children. Laryngoscope. 1993; 103:216-219.

9. Derlacki EL (1953) Repair of central perforation of tympanic membrane. Arch otolaryngol 58:405.

10. Dursun E, Dogru S, Gungor A, Cincik H, Poyrazoglou E, Ozdemir T. Comparison of paper-patch, fat and perichondrium Myringoplasty in repair of small tympanic membrane perforations. Otolaryngol Head Neck Surg 2008;138:353-356.

11. Fiorino F, Barbieri F. Fat graft Myringoplasty after unsuccessful tympanic membrane repair. Eur Arch Otolaryngol. 2007;264:1125-1128.

12. George G Browning, Saumil N Merchant, Gerard Kelly, Iain RC Swan, Richard Canter and William S McKerrow. Scott-Brown's otolaryngology, head and neck surgery. 7th edition. Chronic Otitis Media. Chapter 237c, Vol., 3. Pages-3396-3445.

13. Gross CW. Bassila M. Lazar RH. Long TE. Stagner S. Adipose plug Myringoplasty: an alternative to formal Myringoplasty techniques in children. Otolaryngol Head Neck Surg. 1989; 101: 617-620.

14. Hagemann M, Hausler R (2003) Tympanoplasty with adipose tissue. laryngorhinootologie 82(6):393-396.

15. Halik JJ, Smyth GD (1988) Long-term results of tympanic membrane repair. Otolaryngol Head Neck Surg 98(2):162-169Kaddour HS. Myringoplasty under local anaesthesia: Day case surgery. Clin Otolaryngol Allied Sci 1992;17:567-8.

16. Kamakshi SK. Role of fat plug in myrinoplasty. Otolaryngol Online J 2011.

17. Kelvin M. Kwong, Matthew M. Smith, James M. Coticchia. Fat graft Myringoplasty using umbilical fat. International Journal of Pediatric Otorhinolaryngology 2012; 1098-1101.

18. Kim DK, Park SN, Yeo SW, et al. Clinical efficacy of fat graft Myringoplasty for perforations of different sizes and locations. Acta Otolaryngol. 2011; 131(1):22-26. 